\title{
カーボンナノチューブのオゾンによる損傷の評価
}

\author{
石川 諒 ${ }^{1,2}$ ・ 中野尭雄 ${ }^{1,3}$ ・島 龍之介 ${ }^{4} \cdot$ 清水麻希 $^{4} \cdot$ 本間芳和 ${ }^{1,4, *}$ \\ ${ }^{1}$ 東京理科大学 グローバルサイエンスキャンパス＼cjkstart函162-8601 東京都新宿区神楽坂 1-3 \\ 2 青山学院高等部 函 150-8366 東京都渋谷区渋谷 4-4-25 \\ 3 横浜サイエンスフロンティア高校②30-0046 神奈川県横浜市鶴見区小野町 6 \\ 4 東京理科大学 理学部 物理学科 函 162-8601 東京都新宿区神楽坂 1-3
}

（2018 年 7 月 3 日受付；2018 年 10 月 15 日掲載決定）

\section{Evaluation of Ozone Damage of Carbon Nanotubes}

\author{
Ryo Ishikawa ${ }^{1,2}$, Akio Nakano ${ }^{1,3}$, Ryunosuke Shima ${ }^{4}$, Maki Shimizu ${ }^{4}$ and Yoshikazu Homma ${ }^{1,4}$, \\ ${ }^{1}$ Global Science Campus, Tokyo University of Science, 1-3 Kagurazaka, Shinjuku-ku, Tokyo 162-8601 \\ ${ }^{2}$ Aoyama Gakuin Senior High School, 4-4-25 Shibuya, Shibuya-ku,Tokyo 150-8366 \\ ${ }^{3}$ Yokohama Science Frontier High School, 6 Ono-cho, Turumi-ku, Yokohama-shi, kanagawa 230-0046 \\ ${ }^{4}$ Department of Physics, Tokyo University of Science, 1-3 Kagurazaka, Shinjuku-ku, Tokyo 162-8601
}

(Received July 3, 2018 ; Accepted October 15, 2018)

\begin{abstract}
Single-walled carbon nanotubes (CNTs) are light and highly tensile, which makes them a candidate material for space elevator. However, CNTs are not resistant to oxidant. We studied the damage of CNTs caused by exposure to ozone using several kinds of single-walled CNTs with varying crystallinity and morphology. We found a correlation between the initial crystallinity and resistance to ozone : high-crystallinity CNTs with a small number of defects were lightly damaged by ozone exposure, while highly-defective CNTs were further damaged. The thickness of bundling also affected the resistance to ozone. High-crystallinity CNTs forming a thick bundle were most resistant to ozone.
\end{abstract}

KEYWORDS : carbon nanotube, ozone exposure, defect, Raman spectroscopy

\section{1.は じ め に}

将来宇宙エレベーターを建設する構想があるが，その ケーブルとして最も有力視されているものはカーボンナ ノチューブ (carbon nanotube : CNT) である ${ }^{1)}$ 。CNT は グラフェンを筒状にした構造をもち, 細長く, 非常に軽 く, 引っ張り方向への強度が非常に強いためケーブルと して適した機械特性を持っている2)。しかし，ケーブル として宇宙空間と地上をつなぐ際には，ケーブルは必ず オゾン層を通過する。オゾンは強い酸化剂として働く性 質があるため ${ }^{3)}$, それによって CNT が損傷を受ける可能 性がある。オゾン処理は CNT 壁の機能化の観点から研 究されてきた ${ }^{3 \sim 5)}$ 。オゾン処理により, 欠陥の多い多層 CNT では外壁に損傷を受けること妾, また, 単層 CNT

*E-mail : homma@rs.tus.ac.jp
と炭素微粒子が共存している場合, 炭素微粒子はオゾン 処理によりエッチングされるが, 単層 CNT はエッチン グされないことが報告されている4)。したがって, CNT のオゾン耐性は CNT の品質（欠陥の量）と関係すると 考えられる。しかし, 損傷と CNT の品質との関係はこ れまで明確には調べられていない。そこで, 我々は, 様 々な製法の単層 CNT をオゾンに暴露したときの損傷を ラマン分光法により評価し, CNT の結晶性や形態と損 傷の大きさとの関係を調べた。

\section{2. 実 験 方 法}

\section{1 試料}

単層 CNT には様々な合成方法がある6)この中から本 研究では 4 種類の単層 CNT の試料を用意した。それら は, 異なる金属触媒を用いて化学気相成長法 (chemical vapor deposition：CVD）で成長した垂直配向 $\mathrm{CNT}^{7,8)}$ 
2 種類，アーク放電法で合成した CNT（アーク放電 CNT)，および eDIPS (enhanced direct injection pyrolytic synthesis）法9)によるCNT（eDIPS-CNT）である。垂直 配向 CNT は基板上に垂直に成長させたものであり， $\mathrm{mm}$ オーダの長さの CNT を高密度に成長することが可能で あるが，結晶性は低( ${ }^{7,10)}$ 。 eDIPS 法9, 11)やアーク放 電 ${ }^{12)}$ よる CNT は結晶性が高いことが知られている。 本研究では, eDIPS-CNT は名城ナノカーボン社製の平 均直径 $1.5 \mathrm{~nm}$ の製品を購入した。垂直配向 CNT は CVD 法によって合成を行った。合成に用いた金属触媒 は $\mathrm{Fe}, \mathrm{Co}$ の二種類で，以下ではそれぞれにより合成し たものを Fe-CNT, Co-CNT と呼ぶ。また，アーク放電 CNT は炭素電極間のアーク放電により合成した。以下 に詳細な合成条件を示す。

垂直配向 $\mathrm{CNT}^{8}{ }^{8}$ : 垂直配向成長が生じる高密度な触媒 粒子を形成するため, 熱酸化シリコン基板上に $\mathrm{Al}$ を真 空蒸着し, その大気酸化により $10 \mathrm{~nm}$ の膜厚のアルミ ナとした。触媒は真空蒸着を用いて微量の $\mathrm{Fe}$ (均一な 膜厚に換算して $0.64 \mathrm{~nm}$ 相当), Co（膜厚 $0.32 \mathrm{~nm}$ 相当） をそれぞれ基板に蒸着した。 $\mathrm{Fe}-\mathrm{CNT}$ の成長は $850^{\circ} \mathrm{C} に$ 打いて $\mathrm{Ar}$ 希釈 $\mathrm{H}_{2}$ (3 vol.\%) $80 \mathrm{sccm}$ と $\mathrm{Ar}$ 希釈 $\mathrm{C}_{2} \mathrm{H}_{2}$ (0.5 vol.\%) $120 \mathrm{sccm}$ の混合ガスを $9.3 \times 10^{5} \mathrm{~Pa}, 30$ 分間 供給して行った。一方, Co-CNT では $850^{\circ} \mathrm{C}$ において $\mathrm{Ar}$ 希釈 $\mathrm{H}_{2}(3 \mathrm{vol} . \%)$ で液体 $\mathrm{C}_{2} \mathrm{H}_{5} \mathrm{OH}$ をバブリングして得 たガス $50 \mathrm{sccm}$ を $9.3 \times 10^{5} \mathrm{~Pa} ， 30$ 分間供給した。それ ぞれ直径が $5 \mathrm{~nm}$ 程度の太めの単層 $\mathrm{CNT}$ が成長してい た。垂直配向 CNT の平均的な高さは 200 500 $\mu \mathrm{m}$ であ った。

アーク放電 CNT : 電極に黒鉛炭素棒, ペレットは炭 素 $2.00 \mathrm{~g}$, ニッケル $0.0294 \mathrm{~g}$ と酸化イットリウム 0.2258 $\mathrm{g}$ を混ぜた物を使用し, 純へリウム䨌囲気で圧力 $2.3 \mathrm{~Pa}$ のもとで放電し合成した。

\section{2 オゾン照射}

用意した試料にオゾナイザ（ENALY 社製，1000BT12）を用いてオゾンを照射した。オゾナイザのオゾン生 成量は酸素供給量 $1.0 \mathrm{~L} / \mathrm{min}$ のとき $20 \mathrm{mg} / \mathrm{min}$ であり, 照射距離は $10 \mathrm{~cm}$, 照射圧力は $0.2 \mathrm{MPa}$, 照射時間は 0 分から 15 分まで変化させた。なお, オゾン層のオゾン の濃度は最大でも $10^{-8} \mathrm{~mol} / \mathrm{L}$ 台であるのに対し ${ }^{13}$, 才 ゾナイザで生成したものは拉よそ $1.5 \times 10^{-3} \mathrm{~mol} / \mathrm{min} て ゙$ あり, CNT はオゾン層よりも高い濃度でオゾンに暴露 されている。

\section{3 損傷評価}

ラマン分光法を用いることによって CNT 試料の結晶 性を評価した。用いた装置はラマン顕微鏡（ナノフォト ン社製 RAMAN11i）で，波長 $532 \mathrm{~nm}$ のレーザー光を使
用した。CNT のラマンスペクトルのうち， G バンド $\left(1580 \mathrm{~cm}^{-1}\right)$ と D バンド (約 $\left.1350 \mathrm{~cm}^{-1}\right)$ のピーク強度 の比（D/G 比）に注目した。 $\mathrm{G}$ バンドは炭素間の $\mathrm{sp}^{2}$ 結 合に由来し, 結晶性が高いほど $\mathrm{G}$ バンドのスペクトル の強度は大きく, また, D バンドは炭素間の $\mathrm{sp}^{2}$ 結合の

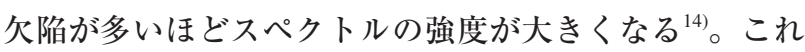
より， D/G 比が小さいほど結晶状態が高いといえる。 オゾン照射時間毎に $\mathrm{G}$ および $\mathrm{D}$ バンドのピークの高さ から $\mathrm{D} / \mathrm{G}$ 比を求めて, オゾンによる損傷の受けやすさ の指標として用いた。

\section{3. 実 験 結 果}

Fig. 1 に各試料のオゾン照射（15 分）前後のラマンス ペクトルを比較して示す。試料によってラマン散乱の強 度比が大きく異なっているが（垂直配向 CNT は剣山の

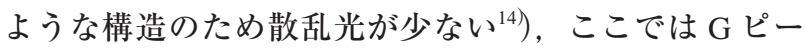
クと D ピークの強度関係に着目する。垂直配向 CNT で ある Fe-CNT および Co-CNT ではオゾン照射によって G ピークが大きく減少し, D ピークが増加した。Co-CNT のほうが D ピークの増加が顕著であるが，照射前には Co-CNT のほうが D ピークが小さいので, D/G 比でみ ると大きな差はない。また, $\mathrm{G}$ ピークの形状も変化し, $1620 \mathrm{~cm}^{-1}$ 付近（図中の个）に久陥に起因する $\mathrm{D}^{\prime}$ バンド と呼ばれるショルダが表れている ${ }^{15)}$ 。両者とも $\mathrm{D} / \mathrm{G}$ 比 が大きく増加した。一方，アーク放電 CNT 抒よび eDIPS-CNT では，オゾン照射によるD ピークの増加は Fe-CNT や Co-CNT に比較して小さい。しかし, G ピー クは両方とも減少しており, 特にアーク放電 CNT は照 射前の $1 / 10$ 程度まで減少した。なお, 両者とも $\mathrm{G}$ ピー クには低波数側（約 $1560 \mathrm{~cm}^{-1}$ ) にショルダがみられ る。これは $\mathrm{G}$ バンドの格子振動のうちチューブの円周 方向の成分 $\left(\mathrm{G}^{-}\right)$に起因するものである ${ }^{14)}$ 。Fe-CNT お よび Co-CNT では結晶性が低いため, $\mathrm{G}^{-}$に起因するシ ョルダは明瞭ではない。

各試料に対して, D/G 比のオゾン照射時間依存性 を Fig. 2 にまとめて示す。走查電子顕微鏡 (scanning electron microscope : SEM）により観察した各試料の形態 も一緒に示した。オゾン照射による $\mathrm{D} / \mathrm{G}$ 比の増加の様 子は試料によって差があるが，オゾン照射初期に $\mathrm{D} / \mathrm{G}$ 比が線形に増加している領域に対して線形フイッテイン グを行い，傾きを求めた。この傾きは，オゾンによる損 傷の増加率を表している。Table 1 に照射前 $\mathrm{D} / \mathrm{G}$ 比と増 加率および 15 分のオゾン照射後の $\mathrm{D} / \mathrm{G}$ 比をまとめる。 照射前の D/G 比は, Fe-CNT と Co-CNT は比較的大き く, アーク放電 CNT と eDIPS-CNT では小さい。 D/G 比 の増加率は Fe-CNT, Co-CNT は大きく, eDIPS-CNT は 
(a)

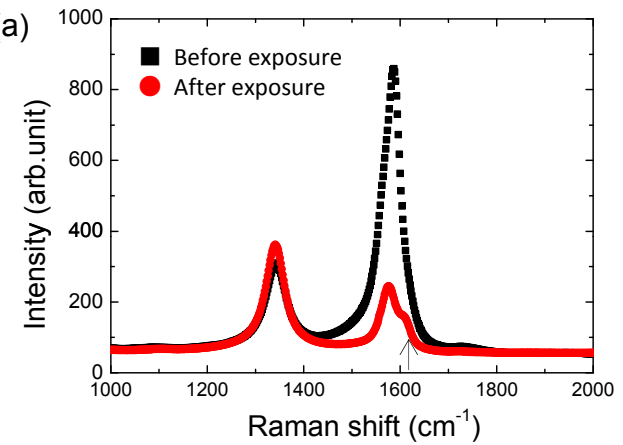

(b)
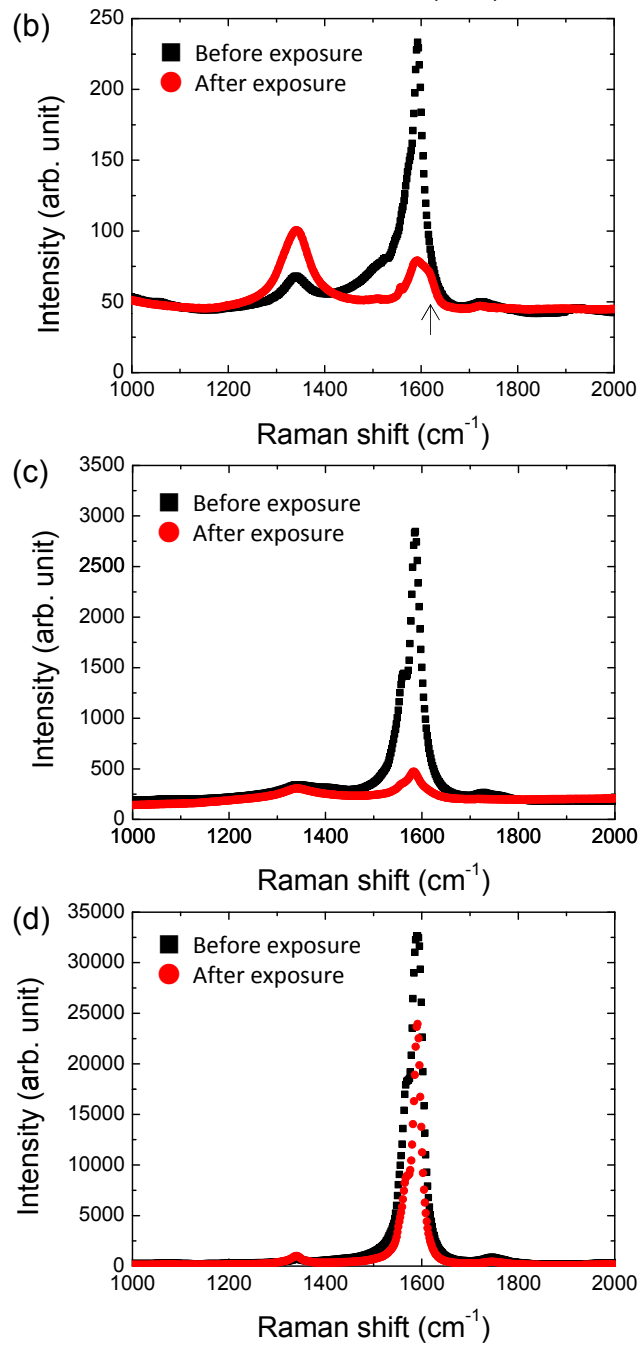

Fig. 1. (color online). Raman spectra of (a) Fe-CNT, (b) CoCNT, (c) Arc-CNT, and (d) eDIPS-CNT before and after 15 min ozone exposure. The arrows in (a) and (b) indicate $\mathrm{G}^{\prime}$ band.

非常に小さい。これより，両者に相関があることがわか る。また $\mathrm{D} / \mathrm{G}$ 比の変化の仕方も異なっており, アーク 放電 $\mathrm{CNT}$ では $\mathrm{D} / \mathrm{G}$ 比が増加し続けているのに対して, Fe-CNT, Co-CNT, eDIPS-CNT では 5〜10 min のオゾン 照射で D/G 比がほぼ一定となった。ただし，Fe-CNT と Co-CNT の場合は $\mathrm{D} / \mathrm{G}$ 比が 2 に近く, 損傷が極めて大
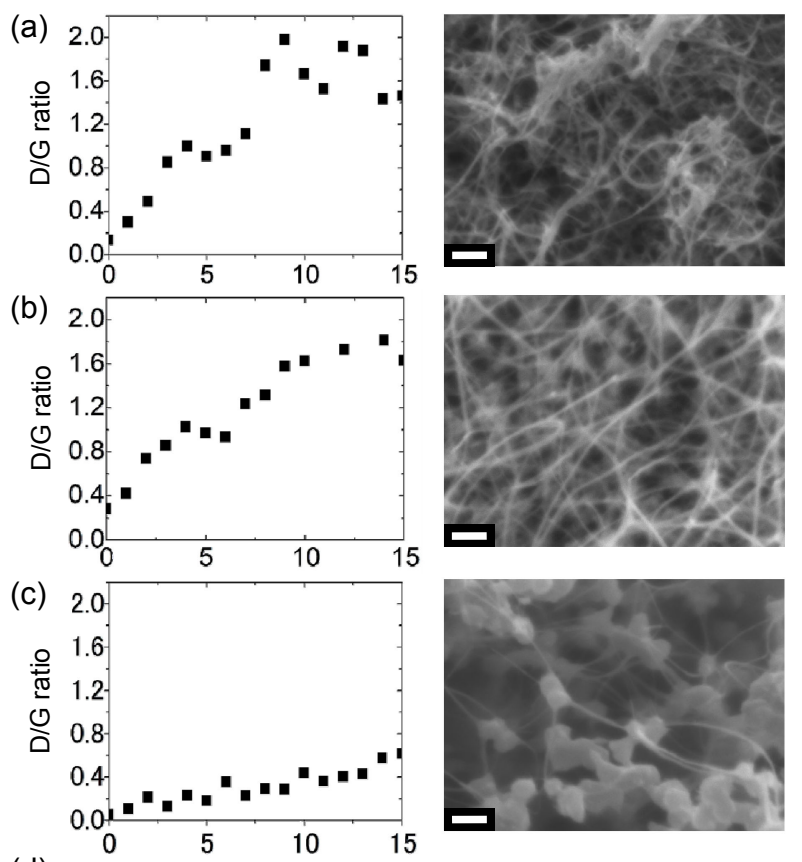

(d)

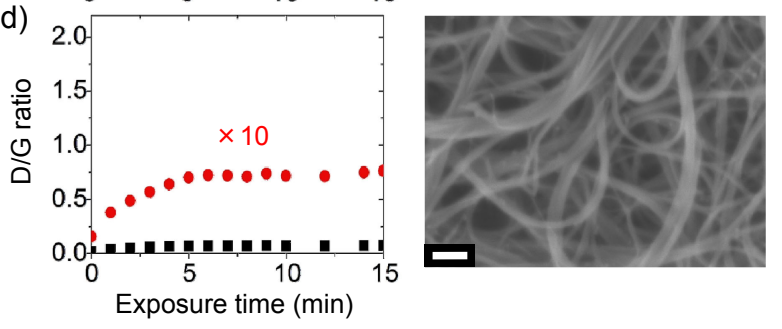

Fig. 2. (color online). Ozone-exposure-time dependence of $\mathrm{D} / \mathrm{G}$ ratio and SEM images for (a) Fe-CNT, (b) Co-CNT, (c) Arc-CNT, and (d) eDIPS-CNT. The data multiplied by 10 $(\times 10)$ are also shown for (d). Scale bar in SEM images corresponds to $100 \mathrm{~nm}$.

Table 1. $\mathrm{D} / \mathrm{G}$ ratio and increasing rate.

\begin{tabular}{lcccc}
\hline & Fe-CNT & Co-CNT & Arc-CNT & eDIPS-CNT \\
\hline Initial D/G & 0.29 & 0.14 & 0.051 & 0.016 \\
Increasing rate & 0.13 & 0.18 & 0.031 & 0.009 \\
Final D/G & 1.56 & 1.6 & $0.6 \uparrow$ & 0.065 \\
\hline
\end{tabular}

$\uparrow:$ Not saturated in $15 \mathrm{~min}$.

きいのに対し, eDIPS-CNT では D/G 比は 0.1 以下であ る。なお, Fig. 1 の結果からわかるように, アーク放電 CNT と eDIPS-CNT の D/G 比の増加は主に G ピークの 減少によるものである。

Fig. 2 の SEM 像では Fe-CNT, Co-CNT, アーク放電 CNT の CNT は細く, eDIPS-CNT の CNT は太く観察さ れた。これは CNT が互いの分子間力により束（バンド ル）を形成するためで, 個々の CNT の直径を考虑する と, 細いバンドルは CNT が数本, 太いバンドルは約 10 〜20 本程度の CNT の集まりと見積られる。一般に, 直 径が均一で直線的な CNT は断面が最密構造の太いバン 
ドルを形成する ${ }^{16)}$ 。また，アーク放電 CNT の SEM 像で は, 粒状の堆積物が付着しているのが観察される。これ はアーク放電では CNT と同時に生成されやすい煤であ ると考えられる。

\section{4. 考察}

まず， D/G 比の増加率が大きい Fe-CNT と Co-CNT に 着目する。これらは, オゾン照射前の $\mathrm{D} / \mathrm{G}$ 比が大きく, 結晶性が低い CNT である。実際, これらの試料の透過 電子顕微鏡（transmission electron microscope：TEM）像 を Fig. 3 に示すように，これらは直径が $5 \mathrm{~nm}$ と太めの 単層 CNT で, 曲がりくねった構造をしている。CNT の TEM 像は電子線と平行な CNT の円筒側面の格子像を示 すもので19)，曲がりくねった形状は明らかに CNT の結 晶性の低さを表す。Co-CNT では比較的直線性の高い部 分がみられるものの, 同様に屈曲部が多く結晶性が低 い。これらの試料で $\mathrm{D} / \mathrm{G}$ 比が 2 程度で飽和する理由は, オゾンが吸着するのはオゾンに直接曝される垂直配向 CNT の上面だけであるのに対し, ラマン散乱は, 光が 垂直配向 CNT に吸収され尽くされずに透過できる 1〜2 $\mu \mathrm{m}$ の厚み ${ }^{177}$ から検出されるためである。すなわち， ラ マン分光では試料表面の CNT が破壊しつくされても, 深い領域のオゾン損傷がない $\mathrm{CNT}$ からの $\mathrm{G}$ ピークも検 出されるため, $\mathrm{D} / \mathrm{G}$ 比が飽和したように見えると考え られる。

次に, D/G 比が増加し続けたアーク放電 CNT につい て考察する。アーク放電 CNT は高温で生成するため, CNT 自体の結晶性は極めて高いものの, 煤などの炭素 不純物が多く含まれており，これらが $\mathrm{D}$ バンドの原因 となっている。オゾン処理によって, 炭素粒子がエッチ ングされることが報告されているが4), 本試料では D ピ 一ク強度はあまり変化していないので, CNT そのもの がエッチングされている可能性もある。CNT の生成量 が少ないためバンドルが細いこと, また, 残留している 触媒金属によるオゾン酸化の触媒作用によりエッチング が進むのではないかと推察される。
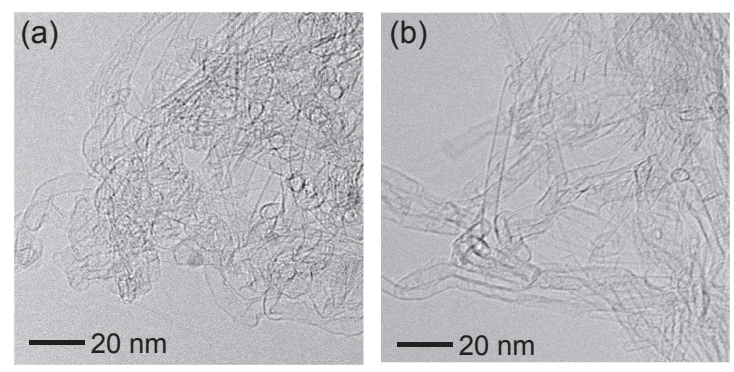

Fig. 3. TEM images of (a) Fe-CNT and (b) Co-CNT.
最後に, D/G 比が小さい值のままで飽和した e-DIPSCNT について考える。この試料では，オゾン損傷が垂 直配向 CNT である Fe-CNT と Co-CNT に比べて極めて 小さい。CNT 本来の結晶性が高い場合には，オゾンに よる損傷を受けにくいことを意味する。垂直配向 CNT の場合と併せて考えると, オゾンはもともと CNT にあ る久陥部に吸着し $\mathrm{sp}^{2}$ 結合を減少させる $(\mathrm{G}$ ピークを減 少させる）ように作用するのに対し，オゾン照射によっ て新たに試料に欠陥が生成される（D ピークを増加させ る）レートはこれより小さいといえる。これは，オゾン 分子が CNT 壁の欠陥である Stone-Wales に化学吸着する のに対し，欠陥のない理想的な CNT 壁には物理吸着し かしないという計算結果と一致する ${ }^{19}$ 。

バンドルの太さもオゾン損傷の多少に関係しているこ とが考えられる。バンドルの内側にある CNT は外側に ある CNT に覆われることによってオゾンに曝される度 合いが低い。したがって，太くバンドルした eDIPSCNT では内側にある CNT の割合が増えることからオゾ ンによる損傷を受ける割合が減ったため, D/G 比の変 化が小さかったと見ることもできる。

\section{5. を と}

本研究では, 様々な種類の単層 CNT 試料を用い, 結 晶性によるオゾン照射損傷の違いを調べた。損傷の大き さはラマンスペクトルにおける $\mathrm{D}$ バンドと $\mathrm{G}$ バンドの 強度比（D/G 比）を用いて評価した。この結果, 結晶 性の低い垂直配向 CNT では $\mathrm{D} / \mathrm{G}$ 比が数倍から一枌増加 したのに対し, 結晶性の高い CNT ではオゾン照射によ る $\mathrm{D} / \mathrm{G}$ 比の増加率は小さく, かつ一定值で飽和する傾 向がみられた。また, 結晶性が高く直線性の良い CNT では太いバンドルが形成されており, バンドル内部の CNT がオゾン損傷を受けにくいことも D/G 比の増加が 抑えられることに寄与していると考えられる。今回の研 究から, 欠陥の少ない CNT はオゾンによって傷つきに くいこと，またバンドルが太いなど，内部の CNT がオ ゾンに曝されにくい構造を持っているものは損傷の増加 率が小さいということが分かった。

\section{謝 辞}

本研究は, 国立研究開発法人科学技術振興機構「グロ ーバルサイエンスキャンパス」委託事業の支援を受け て, 2017 年度に石川 諒（当時高校 2 年生）が東京理科 大学理学部第一部物理学科本間研究室において実施して ものである。中野克雄（当時高校 2 年生）はアーク放 電 CNT の合成を行った。本委託事業より研究の機会と 研究経費の補助をいただいた。 


\section{文献}

1）一般社団法人宇宙エレベーター協会 : “宇宙エレベ ーターとは” http://www.jsea.jp/about-se/

2) 齋藤理一郎 : “フラーレン・ナノチューブ・グラフ エンの科学” (共立出版, 2015).

3) J.M. Simmons, B.M. Nichols, S.E. Baker, M.S. Marcus, O.M. Castellini, C.-S. Lee, R.J. Hamers and M.A. Eriksson : J. Phys. Chem. B 110, 7113 (2006).

4) P.P. Pal, T. Larionova, I.V. Anoshkin, H. Jiang, M. Nisula, A.A. Goryunkov, O.V. Tolochko, M. Karppinen, E.I. Kauppinen and A.G. Nasibulin : J. Phys. Chem. C 119, 27821 (2015).

5) J. Luo, Y. Liu, H. Wei, B. Wang, K.-H. Wu, B. Zhang and D.S. Su : Green Chem. 19, 1052 (2017).

6) フラーレン・ナノチューブ・グラフェン学会編 : “カーボンナノチューブ・グラフェンハンドブック” (コロナ社, 2011) pp. 1-55.

7) H. Ohno, D. Takagi, K. Yamada, S. Chiashi, A. Tokura and Y. Homma : Jpn. J. Appl. Phys. 47, 1956 (2008).

8) A. Kaneko, K. Yamada, R. Kumahara, H. Kato and Y. Homma : J. Phys. Chem. C 116, 26060 (2012).

9) T. Saito, S. Ohshima, T. Okazaki, S. Ohmori, M. Yumura and S. Iijima : J. Nanosci. Nanotechnol. 8, 6153 (2008).
10) S. Yasuda, D.N. Futaba, T. Yamada, J. Satou, A. Shibuya, H. Takai, K. Arakawa, M. Yumura and K. Hata : ACS Nano 3, 4164 (2009).

11) L. Shi, P. Rohringer, P. Ayala, T. Saito and T. Pichler : Phys. Status Solidi B 250, 2611 (2013).

12) H. Li, L. Guan, Z. Shi and Z. Gu : J. Phys. Chem. B 108, 4573 (2004).

13) American Meteorological Society : Glossary of Meteorology, “ozonosphere” http://web.archive.org/web/ 20070214133231/http://amsglossary.allenpress.com:80/ glossary/search?id=ozonosphere 1

14) K. Mizuno, J. Ishii, H. Kishida, Y. Hayamizu, S. Yasuda, D.N. Futaba, M. Yumura and K. Hata : Proc. Natl. Acad. Sci. U.S.A. 106, 6044 (2009).

15) R. Saito, M. Hofmann, G. Dresselhaus, A. Jorio and M.S. Dresselhaus : Adv. Phys. 60, 413 (2011).

16) A. Thess, R. Lee, P. Nikolaev, H. Dai, P. Petit, J. Robert, C. Xu, Y.H. Lee, S.G. Kim, A.G. Rinzler, D.T. Colbert, G.E. Scuseria, D. Tomanek, J.E. Fischer and R.E. Smalley : Science 273, 483 (1996).

17) S. Iijima : Nature 354, 56 (1991).

18) S. Maruyama, E. Einarsson, Y. Murakami and T. Edamura : Chem. Phys. Lett. 403, 320 (2005).

19) S. Picozzi, S. Santucci, L. Lozzi, L. Valentini and B. Delley : J. Chem. Phys. 120, 7147 (2004). 